Atmos. Chem. Phys., 13, 10989-11003, 2013

www.atmos-chem-phys.net/13/10989/2013/

doi:10.5194/acp-13-10989-2013

(c) Author(s) 2013. CC Attribution 3.0 License.

\title{
Immersion freezing of birch pollen washing water
}

\author{
S. Augustin ${ }^{1}$, H. Wex ${ }^{1}$, D. Niedermeier ${ }^{1}$, B. Pummer ${ }^{2,3}$, H. Grothe ${ }^{2}$, S. Hartmann ${ }^{1}$, L. Tomsche ${ }^{1}$, T. Clauss ${ }^{1}$, \\ J. Voigtländer ${ }^{1}$, K. Ignatius ${ }^{1}$, and F. Stratmann ${ }^{1}$ \\ ${ }^{1}$ Leibniz Institute of Tropospheric Research, Permoserstr. 15, 04318 Leipzig, Germany \\ ${ }^{2}$ Institute of Material Chemistry, Vienna University of Technology, Austria \\ ${ }^{3}$ Max Planck Institute for Chemistry, Hahn-Meitner-Weg 1, 55128 Mainz, Germany \\ Correspondence to: S. Augustin (augustin@tropos.de)
}

Received: 14 November 2012 - Published in Atmos. Chem. Phys. Discuss.: 19 December 2012

Revised: 26 September 2013 - Accepted: 8 October 2013 - Published: 11 November 2013

\begin{abstract}
Birch pollen grains are known to be ice nucleating active biological particles. The ice nucleating activity has previously been tracked down to biological macromolecules that can be easily extracted from the pollen grains in water. In the present study, we investigated the immersion freezing behavior of these ice nucleating active (INA) macromolecules. Therefore we measured the frozen fractions of particles generated from birch pollen washing water as a function of temperature at the Leipzig Aerosol Cloud Interaction Simulator (LACIS). Two different birch pollen samples were considered, with one originating from Sweden and one from the Czech Republic. For the Czech and Swedish birch pollen samples, freezing was observed to start at -19 and $-17^{\circ} \mathrm{C}$, respectively. The fraction of frozen droplets increased for both samples down to $-24^{\circ} \mathrm{C}$. Further cooling did not increase the frozen fractions any more. Instead, a plateau formed at frozen fractions below 1 . This fact could be used to determine the amount of INA macromolecules in the droplets examined here, which in turn allowed for the determination of nucleation rates for single INA macromolecules. The main differences between the Swedish birch pollen and the Czech birch pollen were obvious in the temperature range between -17 and $-24^{\circ} \mathrm{C}$. In this range, a second plateau region could be seen for Swedish birch pollen. As we assume INA macromolecules to be the reason for the ice nucleation, we concluded that birch pollen is able to produce at least two different types of INA macromolecules. We were able to derive parameterizations for the heterogeneous nucleation rates for both INA macromolecule types, using two different methods: a simple exponential fit and the Soccer ball model. With these parameterization methods we were able to describe the
\end{abstract}

ice nucleation behavior of single INA macromolecules from both the Czech and the Swedish birch pollen.

\section{Introduction}

As ice nucleation in clouds influences precipitation initiation and radiative forcing (Pruppacher and Klett, 1997; Lohmann et al., 2002; Storelvmo et al., 2011), it plays an important role for both climate and weather. Ice formation in clouds occurs either through homogeneous or heterogeneous ice nucleation. For the latter case, an insoluble particle called an ice nucleus (IN) lowers the energy barrier for the phase transition from liquid water to ice, causing freezing at higher temperatures than homogeneous ice nucleation. To understand the glaciation of clouds and to be able to model clouds, the knowledge about the ice nucleation ability and thus the heterogeneous nucleation rate of the IN that are present in the atmosphere is necessary. Investigations of ice crystal residues in an air mass sampled in the western USA showed that, in this particular case, about one-third of the atmospheric IN were of biological origin (Pratt et al., 2009). Additionally, Pratt et al. (2009) stated that $60 \%$ of the dust particles were likely to be internally mixed with humic and/or biological material. Also, Schnell and Vali (1972) and Conen et al. (2011) showed that mineral samples containing organic material froze at higher temperatures than pure mineral samples, and Schnell and Vali (1976) suggested that clay particles may act as inert carriers of biological materials.

Biological particles - which include bacteria, viruses, spores, plant and insect fragments, algae and pollen - are known to nucleate ice at much higher 
temperatures than nonbiological particles, e.g., mineral dust (Szyrmer and Zawadzki, 1997; Murray et al., 2012). In the case of bacteria, ice-nucleating proteins (INP) are responsible for the ice nucleation (e.g., Wolber et al., 1986; Govindarajan and Lindow, 1988, Hartmann et al., 2013). They are thought to act as templates onto which further water molecules can attach and form ice-like crystalline structures (Graether and Jia, 2001). Thus water molecule clusters are generated that are large enough to initiate freezing at temperatures far above the homogeneous freezing point (up to $-2{ }^{\circ} \mathrm{C}$; see Maki et al., 1974).

In the case of pollen, there have only been a few experimental investigations. The high hygroscopicity of pollen was already shown by Durham (1941) and Dingle (1966), but still little is known about their ice nucleating ability. Diehl et al. (2001, 2002) and von Blohn et al. (2005) performed some measurements with different pollen types in a wind tunnel. They found that pollen grains are active ice nuclei in the immersion and condensation mode but not in the deposition mode. Median freezing temperatures of $-13.8,-15.8$ and $-16.2^{\circ} \mathrm{C}$ were found for birch pollen, oak pollen, and grass and pine pollen, respectively. Also Pummer et al. (2012) identified birch pollen as the most ice-active pollen type. In that study 15 different pollen species were investigated in an oil emulsion on a cryostage microscope. Birch, pine and juniper pollen showed the highest median freezing temperatures with $-19,-20$ and $-21^{\circ} \mathrm{C}$, respectively. As these species usually occur up to the northern timberline, it was assumed that this mechanism protects the plant from frost damage (Pummer et al., 2012).

Pollen grains are the male gametes (sexual reproduction cells) of spermatophytes (seed-producing plants). In order to fertilize a female pistil, pollen has to be transported, either by flying animals, water or wind. Wind-distributed pollen grains are emitted by plants in high numbers into the air. Consequently, they are present in the atmospheric aerosol. However, as generally pollen grains have sizes between 10 and $100 \mu \mathrm{m}$ in diameter, they are considered to be too large to remain in the atmosphere for a long time, as reported by, e.g., Phillips et al. (2007). They also mentioned that in the case of broken pollen, their small submicron fragments could be numerous and thus play a more important role in atmospheric processes.

Pummer et al. (2012) found that the pollen bodies themselves are not necessary for the ice nucleation. They investigated a so-called pollen washing water that was produced by suspending pollen in water and removing them afterwards by filtration. In general, the measured median freezing temperatures reported in Pummer et al. (2012) were similar for the whole grains and the respective pollen washing waters. The ice activity of the pollen washing waters could be attributed to extractable compounds with masses between 100 and $300 \mathrm{kDa}$, which was determined via size-selective filtration. It is known that the pollen surface is covered with huge amounts of compounds (e.g., Breiteneder et al., 1989; Clarke et al., 1979; Schulte et al., 2009), with many of them being easily extractable in water. Another source for pollen material is the interior of the pollen that can become accessible by the bursting of grains in water (Schäppi et al., 1999). Further investigation with bioanalytical techniques, such as chemical and enzymatic degradation experiments, has shown that the ice-active pollen compounds are macromolecules with no or unimportant proteinaceous content (Pummer et al., 2012). Therefore, polysaccharides are the most likely candidate for being the ice-active compounds since they commonly occur on the pollen surface.

The occurrence of independent allergens and sugars in the atmosphere, originating from pollen, has previously been reported in the literature (Yttri et al., 2007; Schäppi et al., 1999). According to these studies, bursting of pollen grains by rainfall is thought to be the most probable source. Schäppi et al. (1999) observed that the concentration of allergens and sugars in the atmosphere is 10 times higher on rainy days than on dry days. Consequently, fragments of pollen and/or substances washed out of pollen could play an important role in atmospheric ice nucleation as both fragmentation and washing processes may significantly increase the number and lifetime of ice nuclei compared to the pure pollen.

Therefore, we used the Leipzig Aerosol Cloud Interaction Simulator (LACIS; Stratmann et al., 2004; Hartmann et al., 2011) to investigate the freezing behavior of particles generated from birch pollen washing water. As mentioned above, Pummer et al. (2012) have already defined the responsible freezing entities in the pollen washing water as nonproteinaceous macromolecules. Here we quantified the ice nucleation ability of these ice nucleation active (INA) macromolecules as a function of temperature. In contrast to the existing studies, we investigated droplets containing only one size-segregated particle. We were able to produce these particles in a way that they contained none, one or a very small number of INA macromolecules. Due to this, the newly developed CHESS model (Hartmann et al., 2013) could be used to derive the effective heterogeneous ice nucleation rate of the INA macromolecules.

\section{Material and measurement method}

\subsection{Material preparation and particle generation}

For the measurements we used two different birch pollen samples from different origins. One sample was ordered from Pharmallerga ${ }^{\circledR}$ and originated from the Czech Republic (in the following it will be called Czech birch). The other sample contained pollen from Sweden (in the following it will be called Swedish birch) and was obtained from Allergon $A B^{\circledR}$. In both cases the birch species was Betula pendula. The pollen samples were cleaned by the companies through size separation in a cyclone. The final product meets the purification degree necessary for pharmaceutical use (as these 
samples are usually used by allergologists). In order to keep the sample as natural as possible, we requested that no further treatments (e.g., defatting) be carried out. Both birch pollen samples considered in our study originated from the same batch as the birch pollen used in Pummer et al. (2012). The measurement preparations, procedures and conditions were identical for both samples.

The preparation of the pollen washing water was done in exactly the same way as it had been done in Pummer et al. (2012). First we suspended $1 \mathrm{~g}$ of pollen in $20 \mathrm{~mL}$ of deionized water. After shaking the suspension it was placed in the refrigerator over night. The next day, the suspension was shaken again before the pollen grains were removed by filtering (round filter, Schleicher and Schüll Selecta 595, pore size 4-7 $\mu \mathrm{m}$ ). Pummer et al. (2012) examined transmission electron microscopy pictures of the dried pollen extracts to ensure that there were no submicron fragments of pollen grains that could have been responsible for the observed IN activity. Additionally, Pummer et al. (2012) showed that the ice-active compounds in the pollen suspension are actually much smaller than the pore size of the filters, since even filtration with $300 \mathrm{kDa}$ Vivaspin tube filters did not lead to a decline in the ice activity of the suspensions.

The outer shell of pollen consists of sporopollenin, which is a heterogeneous, tough and rather hydrophobic organopolymer. Various biomolecules such as proteins, sugars, polysaccharides, fats and volatile organic compounds (e.g., Clarke et al., 1979; Breiteneder et al., 1989) are located on the surface of this polymer, and these biomolecules were suspended in the washing water. Additionally, pollen grains may also burst upon contact with water (e.g., Schäppi et al., 1999), so our suspensions might also contain material from the pollen interior. In nature, both the outer surface of the pollen and also the pollen interior are possible sources for the release of material from pollen. In the former case, material can just be washed off through contact with water (rain, surface waters); in the latter case, the bursting of pollen can be initiated upon contact with water. Therefore, although it is not known if the material we examine originates from outside or inside of the pollen, it does not matter in the study presented here, since we want to characterize the birch pollen IN in general. As we used the same batch of birch pollen and the same procedure for preparing the pollen washing water as Pummer et al. (2012), we assume that the ice nucleating active compounds are macromolecules with no or unimportant proteinaceous content (Pummer et al., 2012).

An atomizer (following the design of TSI 3075) was used to generate droplets from the pollen washing water, and afterwards these droplets were dried by passing them through a silica gel diffusion dryer. As the pollen washing water consists of a mixture of several substances, the resulting particles also consist of these different biomolecules, including the INA macromolecules. Subsequent to particle generation, the dry particles were size-selected using a differential mobility analyzer (DMA; Knutson and Whitby, 1975; type "Vi- enna medium") in a range between 100 and $800 \mathrm{~nm}$ (mobility diameter) and then fed into LACIS.

\subsection{LACIS}

In this section, the LACIS setup and operating principle are described briefly. For more detailed information see Niedermeier et al. (2010) and Hartmann et al. (2013, 2011). In Fig. 1, the schematic setup of the LACIS flow tube is shown. LACIS itself consists of seven connected $1 \mathrm{~m}$ tube sections with an inner diameter of $15 \mathrm{~mm}$. The wall temperature of each tube section is set separately by different thermostats (TH). In the inlet section of LACIS, the aerosol flow is combined isokinetically with a humidified sheath air flow such that the aerosol forms a beam of approximately $2 \mathrm{~mm}$ in diameter along the center line of the flow tube. By cooling the tube walls, well-defined temperature and supersaturation profiles with respect to water and ice can be achieved along the center of the flow tube where the aerosol beam is placed. When passing through the flow tube, the cooling leads to the activation of the dry particles to droplets and due to further cooling the droplets may freeze. It should be noted that inside LACIS, each droplet contains only one single particle, and in the case of the size-segregated measurements performed in the framework of the present paper, all immersed particles feature the same mobility diameter. At the outlet of LACIS, the Thermally Stabilized Optical Particle Spectrometer (TOPS-ICE, developed and built at TROPOS; Clauss et al., 2013) is used to determine the number and the phase state of the hydrometeors. By means of TOPSICE, the ice fraction (number of frozen droplets divided by the total number of frozen and unfrozen droplets) and the size of the droplets and ice particles can be analyzed. For the present investigations, with this setup ice fractions down to $1 \%$ can be determined with acceptable measurement uncertainties, while below this limit the significantly increasing measurement uncertainties generally inhibit the use of the data. For the investigation of the immersion freezing behavior of birch pollen washing water, ice fractions in the temperature range between -17 and $-35^{\circ} \mathrm{C}$ were determined. For more detailed information about the operation mode of LACIS, see Hartmann et al. $(2013,2011)$.

\section{Results}

\subsection{Czech birch pollen washing water}

Figure 2 shows the experimental results of the immersion freezing behavior of particles generated from Czech birch pollen washing water. The ice fraction is plotted as a function of temperature for five different particle sizes (mobility diameter $D_{\mathrm{p}}: 150,300,500,650$ and $800 \mathrm{~nm}$ ). Error bars given in Fig. 2 (as well as in all other figures) are standard deviations in those cases where ice fractions were measured at least on three separate occasions for a specific particle size and 


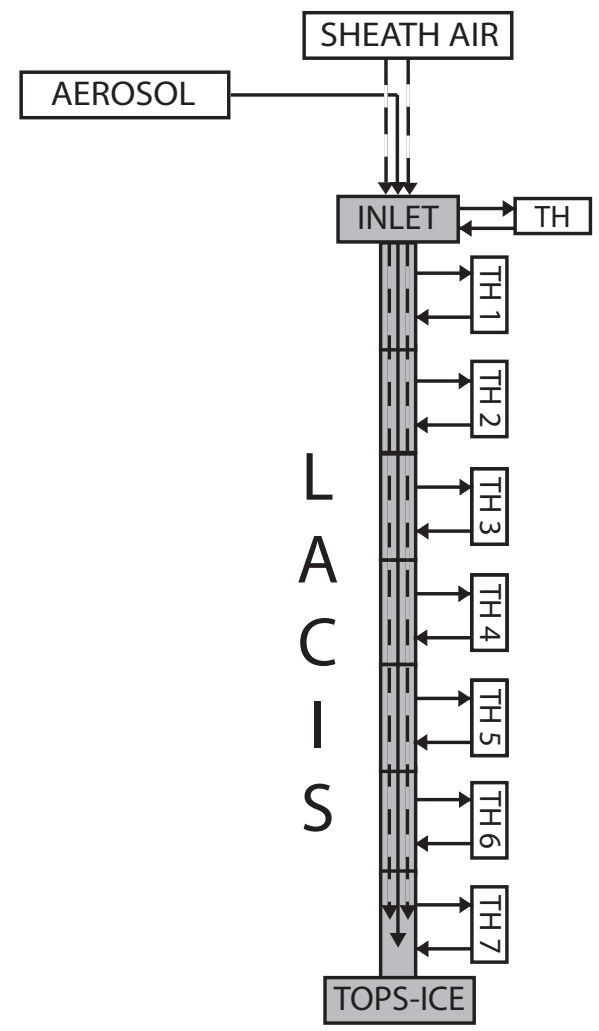

Fig. 1. Setup of the LACIS flow tube. The abbreviation TOPS-ICE stands for Thermally Stabilized Optical Particle Spectrometer.

temperature. However, such a standard deviation could not always be obtained. In these cases, we report error bars based on counting statistics of TOPS-ICE (the number of droplets counted per measurement was at least around 2000), which, as we know from former experience, are equal to or smaller than those based on standard deviations from repeated measurements.

For 300, 500 and $800 \mathrm{~nm}$ particles, the ice fraction was analyzed as a function of temperature in a range from -19 to $-35^{\circ} \mathrm{C}$. First, the logarithm of the ice fractions increases linearly with decreasing temperature in the temperature range between -19 and $-23^{\circ} \mathrm{C}$. With further cooling, the ice fraction curves level off to constant values, suggesting a saturation behavior of the immersion freezing process.

In our study, the ice fraction values at the saturation level $f_{\text {ice }}^{\star}$ (see ice fractions at $-35^{\circ} \mathrm{C}$ ) are size dependent, e.g., 0.03 and 0.7 for 150 and $800 \mathrm{~nm}$ particles, respectively. In the left panel of Fig. 3, $f_{\text {ice }}^{\star}$ is plotted as a function of particle mobility diameter. In general, $f_{\text {ice }}^{\star}$ increases with increasing mobility diameter $D_{\mathrm{p}}$.

In the case of pollen, Pummer et al. (2012) suggested that single sugar-like macromolecules, possibly polysaccharides, are responsible for the ice nucleating ability of pollen. Due to washing the pollen grains, different biomolecules, including these INA macromolecules, can be separated from the pollen

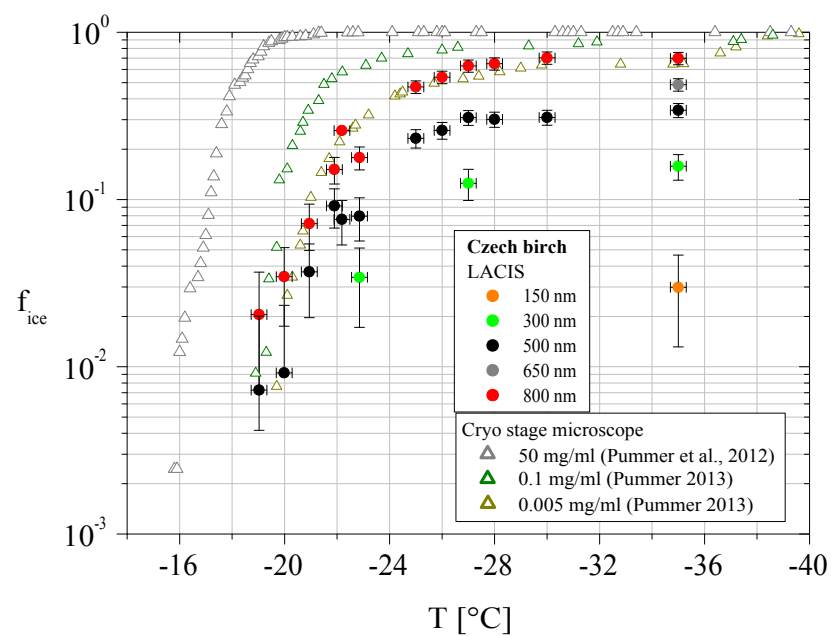

Fig. 2. Ice fraction $f_{\text {ice }}$ as a function of temperature $T$ for 150,300 , 500,650 and $800 \mathrm{~nm}$ Czech birch pollen washing water particles. The filled squares show the LACIS data and the triangles are measurements done by Bernhard Pummer with a cryostage microscope (Pummer et al., 2012, Pummer, 2013).
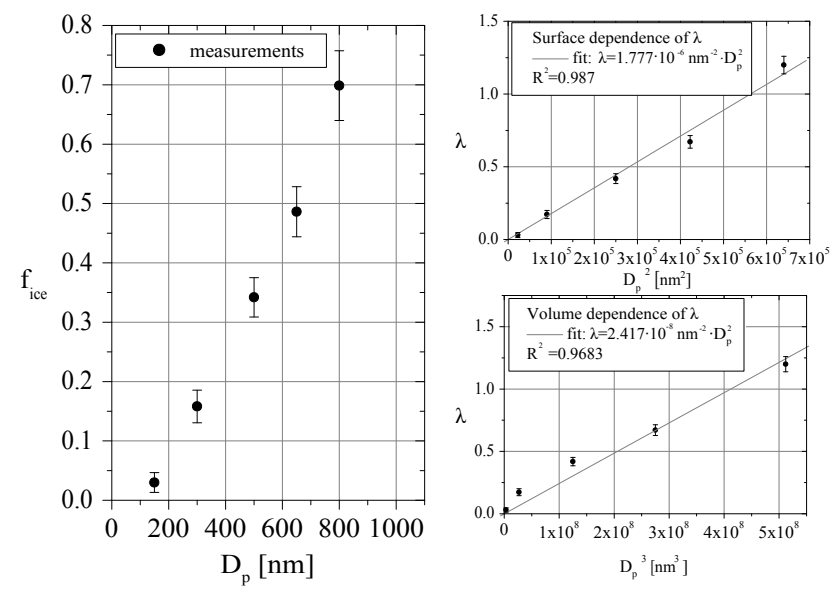

Fig. 3. Ice fraction in the saturation range $f_{\text {ice }}^{\star}$ of the Czech birch pollen washing water particles vs. mobility diameter for $T=$ $-35^{\circ} \mathrm{C}$ (left panel). Expected value $\lambda$ of the Poisson distribution describing the average number of INA macromolecules per Czech birch pollen washing water particle as a function of particle surface $\left(D_{\mathrm{p}}^{2}\right)$ (upper right panel) and as a function of particle volume $\left(D_{\mathrm{p}}^{3}\right)$ (lower right panel). $R^{2}$ is the correlation factor.

bodies (see Sect. 2.1) and become suspended in the washing water. Pummer et al. (2012) reported a median freezing temperature of around $-18^{\circ} \mathrm{C}$ for both birch pollen and birch pollen washing water. The data resulting from their measurements are shown in Fig. 2. The concentration of the birch pollen washing water investigated was the same as in our experiments $(50 \mathrm{mg}$ pollen per $\mathrm{mL}$ water). However when trying to compare between the different results, differences in the operation method need to be considered. Experiments 
with LACIS investigate the freezing of droplets with diameters around $3 \mu \mathrm{m}$, with each droplet grown on a single sizesegregated particle generated from the birch pollen washing water. In the oil emulsion used in Pummer et al. (2012) the droplets are generated directly from the suspension and feature diameters of some tens of micrometers. The absolute mass of pollen material present in these droplets is orders of magnitude higher than the absolute mass considered in our experiments. Assuming that the number of INA macromolecules is related to the mass of pollen material, the number of INA macromolecules per droplet in the experiments by Pummer et al. (2012) is orders of magnitude larger as well. This explains the higher freezing temperatures observed in their experiments.

In Pummer (2013), different and more diluted suspensions were examined for the Czech Birch pollen washing water. Data for these additional suspensions are added to Fig. 2. It was found that for concentrations of $0.1 \mathrm{mg} \mathrm{mL}^{-1}$ and less, not all droplets nucleated ice anymore (i.e., plateau regions similar to those reported in our study appeared), and the fraction of ice nucleating droplets decreased with decreasing concentration.

In our measurements, the atomization of the washing water leads to a distribution of the INA macromolecules to the generated droplets, and after drying of these droplets, particles with or without INA macromolecules are formed. We assume that in the present experiments ice nucleation can only be induced by these single INA macromolecules. Also, from the fact that we find a plateau at $f_{\text {ice }}^{\star}$, we conclude that not all particles contain such an INA macromolecule. Therefore the fraction of particles without any INA macromolecule is defined as $1-f_{\text {ice }}^{\star}$.

Following the approach described in Hartmann et al. (2013), the average number of INA macromolecules per particle is determined by assuming a Poisson distribution of these molecules over the particle population. This Poisson distribution is defined by the expected value $\lambda$ and the stochastic variable $X$ varying in a range of $k=0, \ldots, n$. The probability that a pollen washing water particle contains $k$ INA macromolecules is

$P_{\lambda}(X=k)=\frac{\lambda^{k}}{k !} e^{-\lambda}$.

Due to the fact that the ice fraction $f_{\text {ice }}$ reaches a saturation range with $f_{\text {ice }}^{\star}<1$, we can determine the probability that a particle does not contain an INA macromolecule:

$P(X=0)=\frac{\lambda^{0}}{0 !} e^{-\lambda}=1-f_{\text {ice }}^{\star}$.

Consequently,

$\lambda=-\ln \left(1-f_{\text {ice }}^{\star}\right)$.

The parameter $\lambda$ describes the average number of the INA macromolecules per particle at a given particle size. The respective $\lambda$ values are shown in the right panel of Fig. 3 for different particle surfaces (upper panel) and particle volumes (lower panel). To give an illustrative example, Fig. 3 shows that of all particles with a diameter of $650 \mathrm{~nm}$, roughly $48 \%$ contained at least one INA macromolecule (with a size of roughly $10 \mathrm{~nm}(300 \mathrm{kDa}))$, while the remaining particles in this size range did not contain any INA macromolecules. Poisson distribution in this case tells us that the average number of INA macromolecules per droplet is around 0.7, or, in other words, that 70 INA macromolecules are distributed randomly over 100 generated particles.

As can be seen in Fig. 3, $\lambda$ can be described by both a linear surface area dependence $\left(D_{\mathrm{p}}^{2}\right)$ and a linear volume dependence $\left(D_{\mathrm{p}}^{3}\right)$, illustrated by the linear fits (gray lines). Assuming that the particles activated in LACIS are fully soluble, we would have expected a dependence of $\lambda$ on particle volume only (Hartmann et al., 2013). A possible explanation for the surface area dependence could be that in our experiments the particles produced from the pollen washing water dissolve only partly when being activated inside LACIS and that only the INA macromolecules that were present in the dissolved material induce freezing. When drying pollen washing water, we found that the remnants were a somewhat sticky and sweet-smelling substance resembling honey. This suggests that possibly slowly dissolving substances are contained in the material that is washed off from the pollen, and therefore it could be that the generated particles need more time than the few seconds they have in LACIS to dissolve completely. As our goal is to calculate heterogeneous nucleation rates of single INA macromolecules, the average number of the active INA macromolecules (given by $\lambda$ ) is of interest, independent on how $\lambda$ scales with particle diameter. For the following calculations we decided to use the surface-dependent parameterization for $\lambda\left(\lambda=1.777 \times 10^{-6} \mathrm{~nm}^{-2} \cdot D_{\mathrm{p}}^{2}\right)$, as the correlation factor $\left(R^{2}=0.987\right)$ is slightly better than the correlation factor of the linear volume dependence $\left(R^{2}=0.968\right)$.

In the following, we take a simple approach and assume that all INA macromolecules from the Czech birch pollen that induce freezing are identical. The knowledge of the average number of INA macromolecules per droplet $(\lambda)$ enables us to derive the heterogeneous ice nucleation rate $\left(J_{\text {het }}=\right.$ $S_{\text {site }} j_{\text {het }}$ ) for one single INA macromolecule from the experimentally determined ice fractions, using the CHESS model, described in Hartmann et al. (2013):

$f_{\text {ice }}(T)=1-\exp \left(-\lambda\left(1-\exp \left(-S_{\text {site }} j_{\text {het }}(T) t\right)\right)\right)$.

Here $S_{\text {site }}$ is defined as the ice nucleating surface area of a single INA macromolecule, which is independent of the selected particle mobility diameter. $j_{\text {het }}$ is the heterogeneous ice nucleation rate coefficient. $t$ describes the nucleation time, which is known for LACIS measurements from CFD simulations (see Hartmann et al., 2013). With Eq. (4), the heterogeneous ice nucleation rate $J_{\text {het }}$ with the unit numbers per second (\#/s) can be derived. In Fig. 4, the values for $J_{\text {het }}$ for 300,500 and $800 \mathrm{~nm}$ are shown for the temperature 


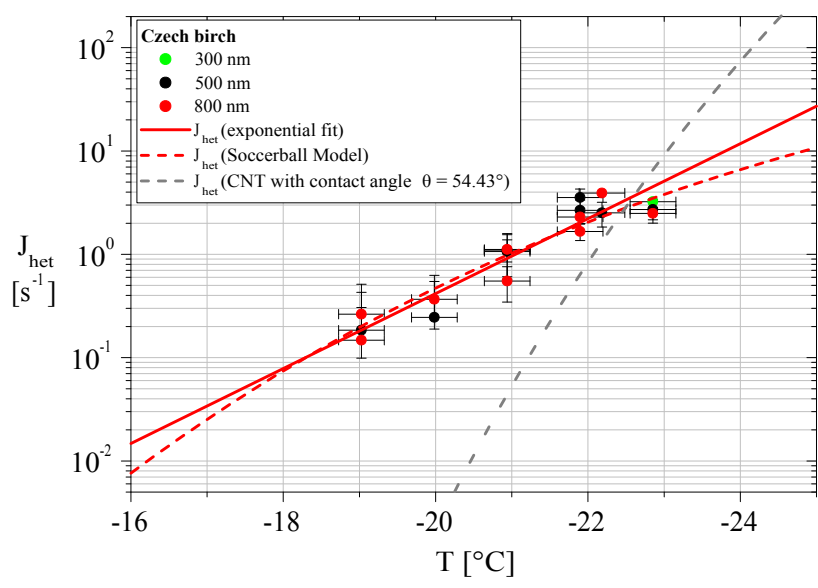

Fig. 4. Heterogeneous ice nucleation rate $\left(J_{\text {het }}\right)$ for 300,500 and $800 \mathrm{~nm}$ particles of Czech birch pollen washing water particles as a function of temperature $T$ (colored dots) and parameterized $J_{\text {het }}$. Straight line: simple exponential fit of $J_{\text {het }}$ with $A=2.320 \times 10^{-8}$ and $B=-0.835^{\circ} \mathrm{C}^{-1}$; dotted line: $\mathrm{SBM}$ with $\mu=58.2^{\circ}$ and $\sigma=$ $4.6^{\circ}$; and gray dotted line: SBM with one contact angle $\mu=54.43^{\circ}$.

range in which the natural logarithm of the ice fraction increases linearly with temperature $\left(-19 \geq T \geq-23^{\circ} \mathrm{C}\right)$.

It can be seen in Fig. 4 that $J_{\text {het }}$ is not a function of the particle diameter. This is to be expected, as the average number of INA macromolecules per particle, i.e., $\lambda$, was accounted for (see Eq. 4). Therefore, $J_{\text {het }}$ now represents a nucleation rate that can be interpreted as being representative for the kind of INA macromolecule occurring on the Czech birch pollen.

With an exponential fit through the $J_{\text {het }}$ values of the different sizes we obtain the following fit function:

$J_{\text {het }}=A \cdot \exp (B \cdot T)$,

with the coefficients $A=2.320 \times 10^{-8} \mathrm{~s}^{-1}$ and $B=$ $-0.835^{\circ} \mathrm{C}^{-1}$. The nucleation rate ranges between $2 \times$ $10^{-1} \mathrm{~s}^{-1}$ at $-19^{\circ} \mathrm{C}$ and $4 \times 10^{0} \mathrm{~s}^{-1}$ at $-23^{\circ} \mathrm{C}$ and is depicted by the straight red line in Fig. 4.

Note that the expression given in Eq. (5) represents a simple way to parameterize the heterogeneous ice nucleation rate as a function of temperature assuming that all INA macromolecules feature the same ice nucleating properties. However, at low temperatures $\left(T<-22^{\circ} \mathrm{C}\right.$, see Fig. 4$)$, the actual nucleation rate is slightly overestimated by this simple parameterization (compare nucleation rate determined from Eq. (5) (straight red line) with the rate that is directly calculated from the measured $f_{\text {ice }}$ (colored dots)). Additionally, we compared the temperature dependence of the derived heterogeneous ice nucleation rate parameterization (Eq. (5)) with one determined applying classical nucleation theory (CNT; e.g., Zobrist et al., 2007) using a single contact angle (dotted gray line in Fig. 4). We found a less pronounced temperature dependence for the parameterized nucleation rate. From Niedermeier et al. (2011b) it can be concluded that this is most likely due to the investigated INA macromolecules not having fully identical ice nucleating properties. This heterogeneity of the INA macromolecules could imply variations in size and/or structure. In other words, although we are investigating the ice nucleation behavior of single INA macromolecules, this does not necessarily imply that all INA macromolecules are fully identical (a detailed discussion concerning possible macromolecule differences leading to slightly different nucleating properties will be given in the discussion section). Therefore, the given parameterization for the nucleation rate (Eq. 5) has to be considered as an effective nucleation rate that is valid for the temperature and time range investigated with LACIS.

We considered a more sophisticated parameterization based on the Soccer ball model (SBM), which combines the CNT with the assumption of a contact angle distribution (Niedermeier et al., 2011b). In contrast to the original method presentation in Niedermeier et al. (2011b), the number of sites per particle is replaced by the average number of INA macromolecules per droplet, namely $\lambda$. Then, with the assumption of the size of a single INA macromolecule as $D_{\mathrm{p}}=10 \mathrm{~nm}$ (Pummer et al. (2012) estimated its size to be about $300 \mathrm{kDa}$ in maximum), the Soccer ball parameters, i.e., mean contact angle $\mu$ and standard deviation $\sigma$, could be determined: $\mu=58.2^{\circ}$ and $\sigma=4.6^{\circ}$. The resulting parameterized nucleation rate is shown also in Fig. 4. Note that the temperature dependence of the individual nucleation rates for the different contact angles originates from CNT. The nucleation rate shown in Fig. 4 is then the result of the integration over all individual nucleation rates. It can be seen that the Soccer ball parameterization represents well the nucleation rate derived from measurements within the entire temperature range investigated.

With the calculated average number of INA macromolecules $(\lambda)$ and the parameterized heterogeneous ice nucleation rate $J_{\text {het }}$ (by the simple exponential fit as well as by the SBM), we can now determine the ice fraction $f_{\text {ice }}$ as a function of temperature for different particle sizes and thus for different $\lambda$ values. In Fig. 5, the results for 300, 500 and $800 \mathrm{~nm}$ particles are shown as straight (simple exponential fit) and dotted lines (SBM). The increase of the ice fraction with decreasing temperature and the different saturation ranges of $f_{\text {ice }}^{\star}$ of the differently sized particles can be simulated by both parameterizations, where the SBM parameterization can represent the data slightly more accurately. This is also illustrated by the least-mean square (see caption of Fig. 5). In Appendix A, additional model results are shown. Calculations were done using either only a single contact angle or omitting the fact that only a fraction of all generated particles carried an INA macromolecule. In all of these cases, no agreement between measurement and calculation was observed.

To summarize, we are able to consistently describe the ice nucleation behavior of the Czech birch pollen washing 


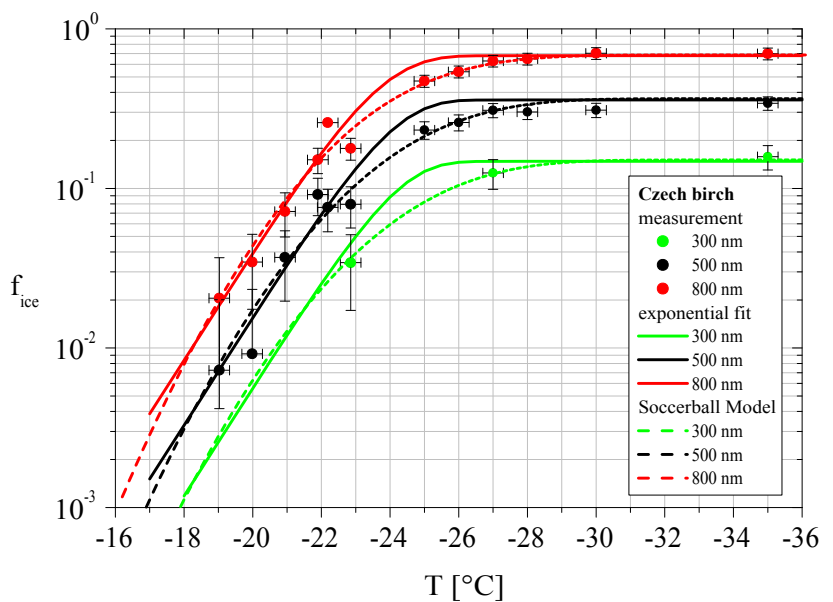

Fig. 5. Ice fraction $f_{\text {ice }}$ as a function of temperature $T$ for 300 , 500 and $800 \mathrm{~nm}$ Czech birch pollen washing water particles (dots) and model calculations for the different sizes (lines) where $J_{\text {het }}$ was calculated based on a simple exponential fit of $J_{\text {het }}$ (straight line) or based on the SBM (dotted line) (see Fig.4). Least-mean square values for 300,500 and $800 \mathrm{~nm}$ particles are $0.144,1.180$ and 0.760 for the simple exponential fit of $J_{\text {het }}$ and $0.004,1.020$ and 0.428 for the SBM, respectively.

water by assuming the number of INA macromolecules to be a function of initial particle size and by an ice nucleation rate, either parameterized by using a simple exponential fit or by a more complicated distribution of contact angles.

\subsection{Swedish birch pollen washing water}

Figure 6 shows the experimental results of the immersion freezing behavior of particles generated from Swedish birch pollen washing water. Again, different mobility diameters $(100,200,300,500,650$ and $800 \mathrm{~nm})$ were considered, with the 300,500 and $800 \mathrm{~nm}$ particles being analyzed in more detail. In the temperature range between -17 and $-20^{\circ} \mathrm{C}$ the ice fractions of the particles generated from the Swedish birch pollen washing water steeply increase with decreasing temperature. Subsequent to this steep increase, the ice fractions rise less steeply and finally reach the saturation range. In the left panel of Fig. 7, the ice fraction in the saturation range $f_{\text {ice }}^{\star}$ for the Swedish birch pollen washing water is plotted against the mobility diameter $D_{\mathrm{p}}$. As for the Czech birch pollen washing water, $f_{\text {ice }}^{\star}$ increases with increasing $D_{\mathrm{p}}$. For $\lambda$ (right panels of Fig. 7), we again found a better agreement between $\lambda$ and $D_{\mathrm{p}}^{2}\left(R^{2}=0.992\right)$ than between $\lambda$ and $D_{\mathrm{p}}^{3}\left(R^{2}=0.928\right)$. Again, as for the Czech birch pollen, one possible explanation for this behavior can be that particles produced from the Swedish birch pollen washing water dissolve only partly when being activated inside LACIS.

We calculated the heterogeneous nucleation rate of the particles generated from the Swedish birch pollen sample in the same way as for the Czech birch pollen sample by as-

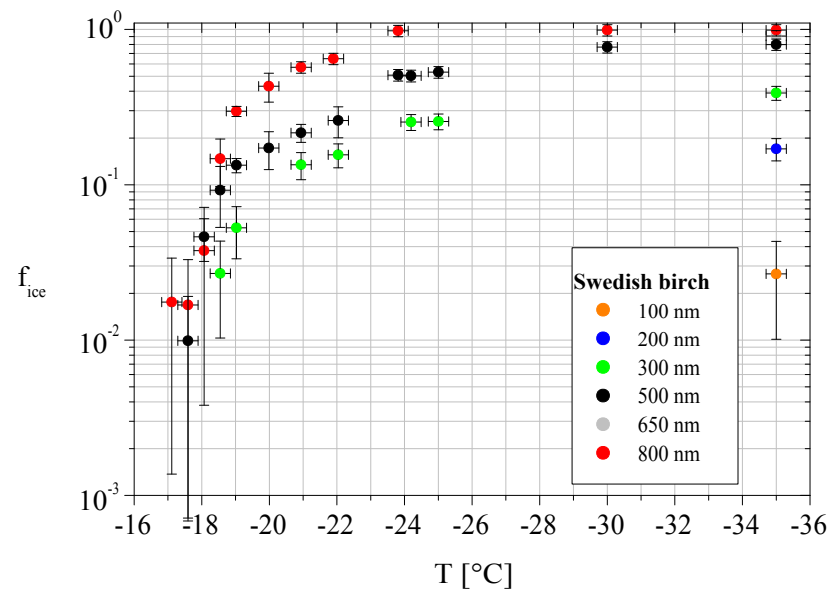

Fig. 6. Ice fraction $f_{\text {ice }}$ as a function of temperature $T$ for 100 , 200, 300, 500, 650 and $800 \mathrm{~nm}$ Swedish birch pollen washing water particles.
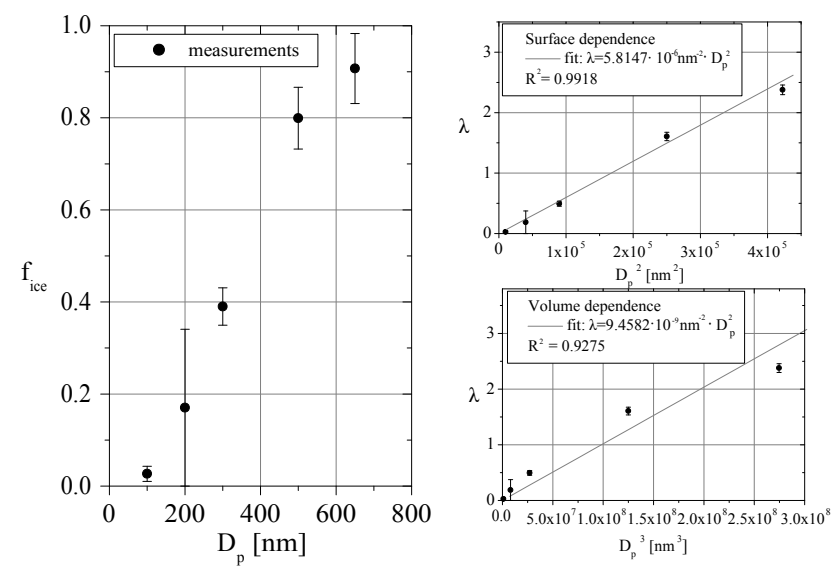

Fig. 7. Ice fraction in the saturation range $f_{\text {ice }}^{\star}$ of the Swedish birch pollen washing water particles vs. mobility diameter for $T=$ $-35^{\circ} \mathrm{C}$ (left panel). Expected value $\lambda$ of the Poisson distribution describing the average number of INA macromolecules per Swedish birch pollen washing water particle as a function of particle surface $\left(D_{\mathrm{p}}^{2}\right)$ (upper right panel) and as a function of particle volume $\left(D_{\mathrm{p}}^{3}\right)$ (lower right panel). $R^{2}$ is the correlation factor.

suming that only one type of INA macromolecules is responsible for freezing. We used the ice fraction measurements in the temperature range in which the natural logarithm of the ice fraction increases linearly with temperature between -17 and $-20^{\circ} \mathrm{C}$. After calculating the ice fraction using the exponential fit parameterization of the heterogeneous nucleation rate $\left(J_{\text {het }}=2.684 \times 10^{-16} \exp \left(-1.893^{\circ} \mathrm{C}^{-1} \cdot T\right) \mathrm{s}^{-1}\right)$ as well as the SBM parameterization $\left(\mu_{\theta}=49.8^{\circ}\right.$ and $\left.\sigma_{\theta}=1.2^{\circ}\right)$ and the determined $\lambda$ values, we noticed that a model including only one type of INA macromolecule could not fully represent our data, as can been seen in Fig. 8. The mean square errors between the measured and the calculated ice fraction 


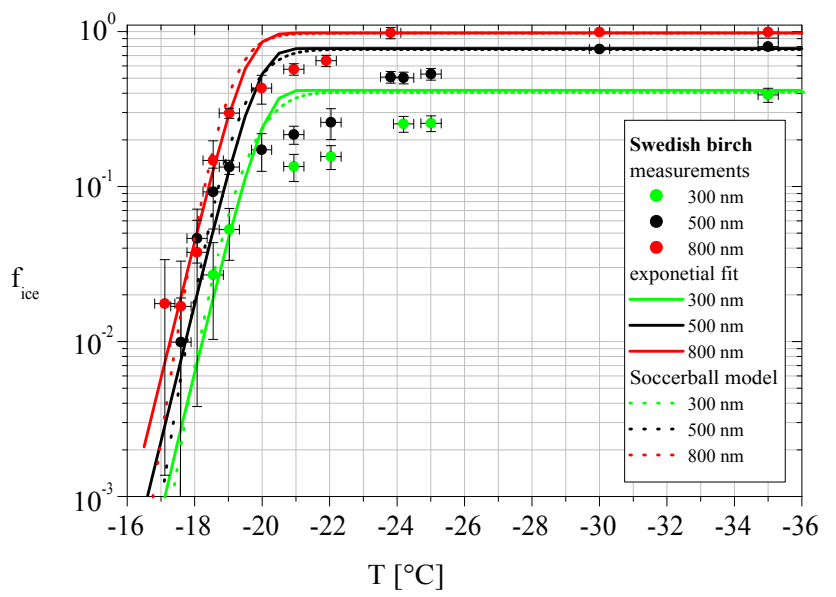

Fig. 8. Ice fraction $f_{\text {ice }}$ as a function of temperature $T$ for 300 , 500 and $800 \mathrm{~nm}$ Swedish birch pollen washing water particles (dots) and model calculations for the different sizes (lines) assuming only one INA macromolecule to be present in the Swedish birch pollen sample. The mean square errors between the measured and the calculated ice fraction for the 300,500 and $800 \mathrm{~nm}$ particles showed values of $7.22,14.47$ and 2.58 for the simple exponential fit of $J_{\text {het }}$ and $6.19,14.70$ and 2.50 for the SBM, respectively.

for the 300,500 and $800 \mathrm{~nm}$ particles showed values of 7.22, 14.47 and 2.58 for the simple approach and 6.19, 14.70 and 2.50 for the SBM, respectively.

A possible explanation for this discrepancy could be that there is more than one kind of INA macromolecule present in the Swedish birch pollen washing water. To clarify this, we used a method (the so-called differential spectra) that was used by Vali (1971) in a similar way to quantify IN that are active at a specific temperature. Therefore the fraction of droplets that froze per temperature interval was calculated for the 500 and $800 \mathrm{~nm}$ particles, i.e., $\left(f_{\text {ice }}\left(T_{2}\right)-f_{\text {ice }}\left(T_{1}\right)\right) /\left(T_{2}-\right.$ $T_{1}$ ) (see Fig. 9). Error bars were obtained by error propagation using the errors for the ice fraction, shown in Figs. 2 and 6 . We observed that the differential spectra of the particles generated from the Czech birch pollen washing water show one mode (within measurement uncertainty), and it can be seen that all the IN become active in the temperature range from roughly -20 to $-27^{\circ} \mathrm{C}$. The particles generated from the Swedish birch pollen washing water, however, show two modes in separate temperature ranges, where one mode occurs roughly in the same temperature range as found for the Czech birch pollen sample. This result for the Swedish birch pollen sample can be interpreted as two different kinds of INA macromolecules being active - one similar to the one found for the Czech birch pollen sample and an additional one being ice active already in the temperature range from -17 to $-20^{\circ} \mathrm{C}$. Despite the small differences between the peaks from the two different samples in the temperature ranges from -20 to $-27^{\circ} \mathrm{C}$, we assume that the respective

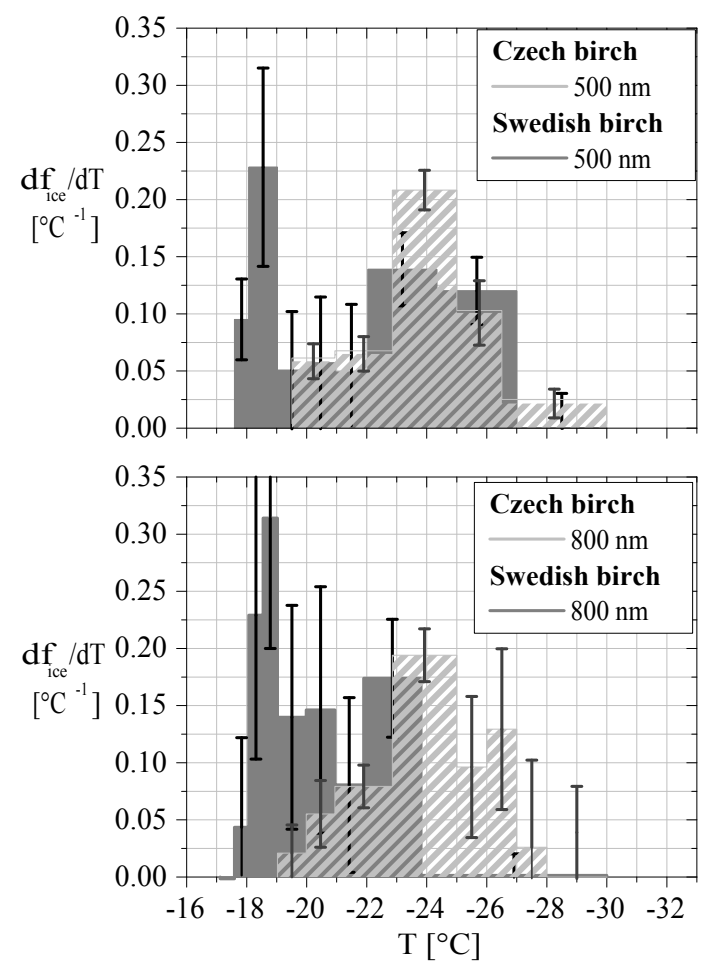

Fig. 9. Change of the ice fraction $f_{\text {ice }}$ per temperature interval for the 500 (upper panel) and $800 \mathrm{~nm}$ (lower panel) particles of the Czech birch pollen washing water (light gray) and the Swedish birch pollen washing water (dark gray).

INA macromolecules are of the same kind. A detailed discussion of these assumptions will be done in Sect. 4 .

In the following the two different types of INA macromolecules will be called INA- $\alpha$ and INA- $\beta$, with INA- $\beta$ being the more IN active macromolecule type that is assumed to be present only in the sample of the Swedish birch pollen and INA- $\alpha$ being the less IN active macromolecule type present in both birch pollen samples. For the further calculations we assume that the ice nucleation rate of INA- $\alpha$, i.e., $J_{\text {het }, \alpha}$, is similar to the one determined for the particles generated from the Czech birch pollen washing water. Additionally, we assume that the average number of INA macromolecules present in the particles is equal to the sum of both the average number of INA- $\beta\left(\lambda_{\beta}\right)$ and INA- $\alpha\left(\lambda_{\alpha}\right)$ :

$\lambda_{\text {tot }}=\lambda_{\alpha}+\lambda_{\beta}$.

To calculate the heterogeneous nucleation rate of the INA$\beta$, i.e., $J_{\text {het, } \beta}$, we again use the CHESS model assuming a combination of INA- $\alpha$ and INA- $\beta$ :

$$
\begin{array}{r}
f_{\text {ice }}(T)=1-\exp \left(-\lambda_{\alpha}\left(1-\exp \left(-\left(J_{\text {het }, \alpha}(T)\right) t\right)\right)\right) \times \\
\times \exp \left(-\lambda_{\beta}\left(1-\exp \left(-\left(J_{\text {het }, \beta}(T)\right) t\right)\right)\right) .
\end{array}
$$

Although $J_{\text {het, } \alpha}$ is known from the Czech birch pollen washing water measurements and $\lambda_{\alpha}$ can be derived from 


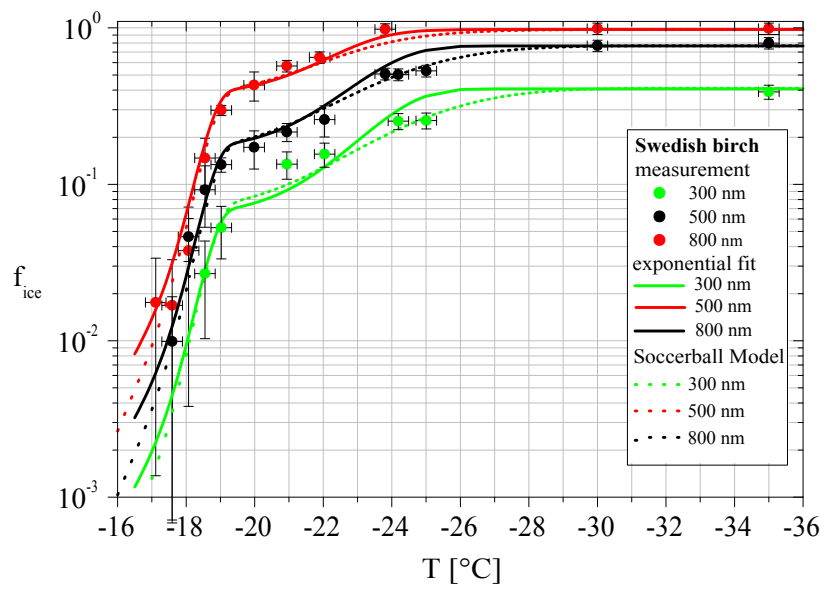

Fig. 10. Ice fraction $f_{\text {ice }}$ as a function of temperature $T$ for 300 , 500 and $800 \mathrm{~nm}$ Swedish birch pollen washing water particles (dots) and model calculations for the different sizes (lines). The model calculation results from the combination of the INA- $\alpha$ and the INA- $\beta$. Therefore the parameterizations found for the INA- $\alpha$ (see Fig. 4) were used. The parameterization for the INA- $\beta$ are $A=9.186 \times 10^{-23}$ and $B=-2.822^{\circ} \mathrm{C}^{-1}$ for the exponential fit of $J_{\text {het, } \beta}$ (straight lines), and $\mu=47.8^{\circ}$ and $\sigma=0.03^{\circ}$ for the SBM (dotted line).

Eq. (6) with $\lambda_{\alpha}=\lambda_{\text {tot }}-\lambda_{\beta}$, we still have two unknown parameters $\left(\lambda_{\beta}\right.$ and $\left.J_{\text {het }, \beta}\right)$. These parameters were determined by fitting Eq. (7) to the whole 500 and $800 \mathrm{~nm}$ data set in an iterative manner. The $300 \mathrm{~nm}$ particles were excluded from the fitting procedure as this data set is considered as too sparse. Again, also the Soccer ball model was used in a similar way by including the parameterization for the contact angle distribution found for the Czech birch pollen washing water to represent INA- $\alpha$ and combine this with another contact angle distribution for INA- $\beta$. Then Eq. (7) was also fitted to the measured ice fraction of the 800 and $500 \mathrm{~nm}$ particles.

Obtained values for the INA- $\beta$ are $A=9.186 \times 10^{-23}$ and $B=-2.822^{\circ} \mathrm{C}^{-1}$ for the exponential fit of $J_{\text {het }, \beta}$, and $\mu=47.8^{\circ}$ and $\sigma=0.03^{\circ}$ for the SBM. Figure 10 shows calculated ice fractions for the two cases (using a simple exponential fit of $J_{\text {het }}$ (straight lines) and the SBM (dotted lines)). Both the two different slopes and the final saturation range $\left(f_{\text {ice }}^{\star}\right)$ are represented very well by the fitted curves. The parameters obtained from the fitting procedure were then used to model $f_{\text {ice }}$ for the $300 \mathrm{~nm}$ particles, and, as can be seen in Fig. 10, the resulting curve also reproduces the measured data well. The mean square errors between the measured and the calculated ice fraction for the 300,500 and $800 \mathrm{~nm}$ particles showed values of $0.44,0.51$ and 1.3 for the simple exponential fit and $0.14,0.51$ and 0.56 for the SBM, respectively. These values are considerably smaller than when we assumed only one type of INA macromolecule to be present in the Swedish birch pollen sample, as shown above. This supports the assumption that at least two differently behav-
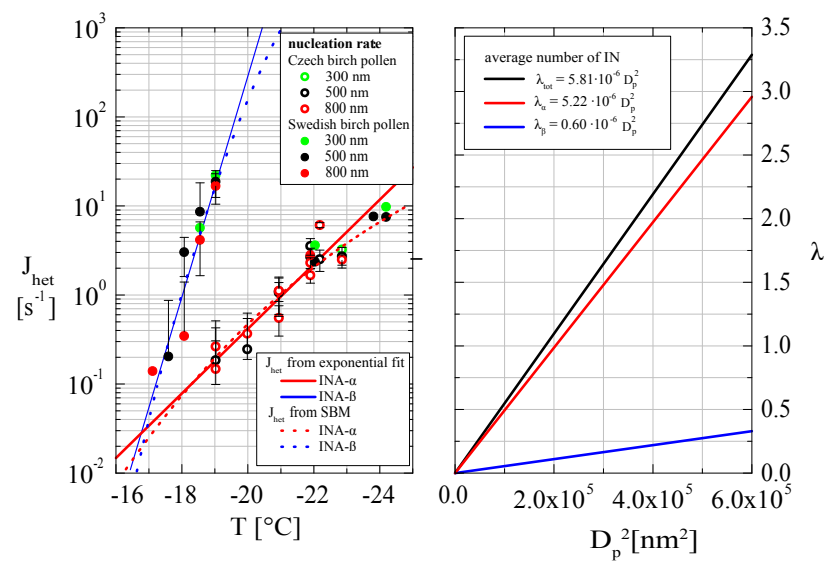

Fig. 11. Left panel: parameterizations of $J_{\text {het, } \alpha}$ (red lines, parameters in caption of Fig. 4 ) and $J_{\text {het, } \beta}$ (blue lines, parameters in caption of Fig. 10). Additionally the $J_{\text {het }}$ values from the measurements are plotted as colored dots and circles. Right panel: $\lambda_{\alpha}, \lambda_{\beta}$ and $\lambda_{\text {tot }}$ of the Swedish birch pollen washing water particles.

ing types of INA macromolecules are internally mixed in the Swedish birch pollen sample, and that one of them is similar to the INA macromolecule type found in the Czech birch pollen washing water. Similar to what was found for the Czech birch pollen, ice nucleation induced by each of these two types of INA macromolecules can be well described by using both approaches, the simple exponential one and the one using a contact angle distribution, with a slightly better performance of the latter.

In Fig. 11, the parameterizations for the heterogeneous nucleation rates for the INA- $\alpha$ and the INA- $\beta$ (left panel) as well as the different $\lambda$ parameterizations (right panel) are shown. It is obvious from the $\lambda$ values that the INA- $\alpha$ macromolecules are much more abundant in the Swedish birch pollen washing water compared to INA- $\beta$ macromolecules. The difference between the two kinds of $J_{\text {het }}$ parameterizations (simple exponential fit and SBM) becomes obvious in the temperature range outside the measured nucleation rates. However, in both cases, $J_{\text {het }, \beta}$ (blue lines) is much steeper than $J_{\text {het, } \alpha}$ (red lines), and the $J_{\text {het, } \beta}$ values lie between $1 \times 10^{-1} \mathrm{~s}^{-1}$ at $-17^{\circ} \mathrm{C}$ and $2 \times 10^{1} \mathrm{~s}^{-1}$ at $-19^{\circ} \mathrm{C}$. Further discussions of this different behavior of the two types of INA macromolecules will follow in the next section.

\section{Discussion}

We investigated the immersion freezing behavior of particles generated from the washing water of two different birch pollen samples (Swedish birch and Czech birch). Both samples showed a saturation range in the frozen fraction at values below 1 . This behavior shows that in our measurements not all droplets contain an INA macromolecule. Pummer (2013) observed a similar behavior when diluting the suspensions 
from $50 \mathrm{mg} \mathrm{mL}^{-1}$ (Pummer et al., 2012) to $0.1 \mathrm{mg} \mathrm{mL}^{-1}$ and less (see Fig. 2). As the number of INA macromolecules contained in the droplets examined by Pummer (2013) can only be roughly estimated (see Appendix B), a more quantitative comparison of these data to ours was not done. However, data from Pummer (2013) show a behavior comparable to our data, particularly the one for a dilution of $0.005 \mathrm{mg} \mathrm{mL}^{-1}$, which coincides with our data for $800 \mathrm{~nm}$ particles. The fact that our data as well as the data from Pummer (2013) show an increase in the levels of the plateau with increasing concentration furthermore corroborate the finding that an increase in the number of ice-active entities in a droplet also increases the temperature at which a droplet will freeze, something that has already been reported for ice-active protein complexes on the bacterium Pseudomonas syringae in Hartmann et al. (2013).

Diehl et al. (2002) presented ice fractions obtained for immersion freezing of birch pollen. In the temperature range where these ice fractions increase, they show a slope similar to our data. Hence it could be assumed that the immersion freezing reported for these and maybe also other pollen in the past was also induced by INA macromolecules. In general, Diehl et al. (2001, 2002) and von Blohn et al. (2005) examined large droplets of sizes of a few hundred micrometers, containing many pollen grains per droplet. According to our hypothesis, these droplets should have included a significantly larger number of INA macromolecules than those examined in our study. And indeed, freezing temperatures reported here are below those reported by Diehl et al. (2001, 2002) and von Blohn et al. (2005), which could be explained by the above-described shift of freezing curves to higher temperatures upon an increase in the number of ice-active entities in the examined droplets.

Furthermore, we observed some differences in the temperature dependence of the immersion freezing behavior between the particles from the Swedish and the Czech birch pollen sample. As the ice fraction of the particles generated from the Czech birch pollen washing water showed a logarithmically linear increase with decreasing temperature (see Fig. 2), we assume that there is only one type of INA macromolecule. In contrast to that the ice fraction of the particles generated from the Swedish birch pollen washing water shows two different slopes (see Fig. 6), with one being much steeper and one being similar to the slope of the particles generated from Czech birch pollen washing water. This could also be shown by the fraction of droplets that froze per temperature interval (Fig. 9). So it seems that birch pollen can express at least two different types of INA macromolecules (INA- $\alpha$ and INA- $\beta$ ), with one being more ice active than the other.

Considering the heterogeneous nucleation rates of these two different types of macromolecules (see left panel of Fig. 11), one notices the big differences in the slope. The heterogeneous nucleation rate for the INA- $\beta$ (blue lines) is much steeper than the heterogeneous nucleation rate for the
INA- $\alpha$ (red lines). Additionally, the contact angle distributions determined for INA- $\alpha$ and INA- $\beta$ by using the SBM were different in that INA- $\beta$ had a lower mean contact angle and a much smaller standard deviation. This indicates that INA- $\beta$ is a more ice active and more homogeneous INA macromolecule concerning the ice nucleating properties than INA- $\alpha$. The reason for that as well as for the seeming existence of two different types of INA macromolecules may lie in the possible different chemical structures of the macromolecules. To clarify this, we have to consider the biological point of view. Biomolecules, like the INA macromolecules we examined here, are usually built up by a sequence of small building blocks, e.g., proteins by amino acids and polysaccharides by monosaccharides. Differences in the structures of these linear or branched chains of units usually lead to changes in the biological function and the biochemical properties of the macromolecule.

Differences could be explained in several ways:

- As the expression of certain macromolecules in a living being is the result of a long-term sequence of spontaneous mutations, it is in principal possible, but unlikely, that one species developed several completely different and very active ice nuclei independently of each other. For example, bacterial ice nucleation can be tracked down to one specific type of a proteinaceous compound (Lindow, 1995). It is more likely that an already existing possibility to express one type of INA macromolecule (i.e., a gene) was altered by additional mutation, leading to the expression of a somewhat different macromolecule that, however, still is ice active.

- For the proper function of a biological macromolecule, the folding is of crucial importance. For example, the misfolding of common prions can make them infectious and cause severe illnesses (Pan et al., 1993). Analogously, the folding of the INA macromolecule in the samples could differ from one to another. Consequently, the structuring effect on the water could be different.

- The exchange of one building block in the sequence of a biological macromolecule can fundamentally change its properties - a phenomenon that is called point mutation and can easily cause differences between different individuals of one species (Takahashi et al., 1994).

- Posttranslational modification of biological macromolecules can be caused by environmental stress, such as exposure to reactive atmospheric trace gases (Franze et al., 2005). As the exposure to stresses depends on location and time, samples taken from different sites are likely to show different behavior.

In the case of the two pollen samples from different origins, the climatic conditions may be responsible for slight differences in the properties of the macromolecules. Already 
Schnell and Vali (1976) found a clear correlation between the abundance of IN in plant litter and the climatic region with an overall increase in IN abundance with latitude. A second reason could be that, for example, due to differences in the degree of maturity, the amount of INA- $\beta$ in the Czech birch pollen is so small that we cannot resolve it with our measurement setup. As our detection limit is at a frozen fraction of $1 \%$, a reduction in abundance of INA- $\beta$ by a factor of 10 , compared to the abundance of INA- $\alpha$, would be enough to hinder the detection with LACIS. However, more biochemical investigations will be necessary to characterize the birch pollen IN and their variability with ambient conditions.

Finally, we will have a short look on the atmospheric application of our measurements. Schäppi et al. (1999) found that concentrations of allergens after rain show a significant increase, which is due to bursting of pollen grains by osmotic shock. In that way, also the INA macromolecules could be separated from the pollen grains. Additionally, as shown by Pummer et al. (2012) and the present study, the INA macromolecules can be easily washed off the pollen, and if this happened in nature, the INA macromolecules could combine with, for example, soil dust and could induce freezing by the respective soil dust particles. A preliminary estimate shows that it is likely that each birch pollen grain carries several thousand macromolecules (see Appendix B). So if they are separated from the pollen grains their concentration in the atmosphere would increase extremely. Due to this large increase of sources for INA macromolecules and due to the long residence times of these nano-sized particles in the atmosphere, ice nucleation due to pollen might play a larger role than, for example, reported in Hoose et al. (2010). It is, however, challenging and far beyond the scope of this study to determine the amount of INA macromolecules from pollen that are present in the atmosphere. First of all, the amount of these molecules produced will differ among different plant species (and even for the same species, as shown in this study). Their small size aggravates detection, and it also needs to be examined how these INA macromolecules, once washed off or otherwise released from the pollen, can become airborne. Also, their lifetime, prior to biological decomposition, is completely unknown. All of these issues should be topics for further research.

We want to add some information concerning the possibility to use the here-gained nucleation rates for atmospheric purposes: it has been shown before that a fitted nucleation rate that well describes a single data set can fail when a different cooling rate or time is considered (e.g., Broadley et al., 2012; Wright and Petters, 2013). The contact angle distribution as obtained with the SBM for INA- $\alpha$ yields a value for $\sigma$ of $4.6^{\circ}$; hence, as discussed above, there seems to be some variation within the different INA- $\alpha$ macromolecules. Therefore, extrapolating the parameterization obtained for INA- $\alpha$ to parameter ranges (with respect to temperature and time) outside of those for which the measurements were made might yield erroneous results. However, the contact angle distribution obtained for INA- $\beta$ is much smaller $\left(\sigma=0.03^{\circ}\right)$; that is, these macromolecules are much more uniform. In this case it can be expected that an extrapolation to different nucleation times or cooling rates is possible. Based on this, the nucleation rate determined for the INA- $\beta$ macromolecule type then is applicable over a wide parameter range.

This nucleation rate then would, for example, represent the source term in the differential equation describing the time evolution of the number concentration of frozen droplets. Alternatively, CHESS model and nucleation rate together could be used for describing ice nucleation by INA macromolecules in larger scale models. This approach allows for the determination of frozen droplet fractions for a given temperature, time and $\lambda$ without solving a differential equation. In this context we want to make an additional remark: the term $1-\exp \left(-S_{\text {site }} j_{\text {het }}(T) t\right)$ in Eq. (4) represents the cumulative distribution function of the exponential distribution. This implies that $\tau=1 / S_{\text {site }} j_{\text {het }}=1 / J_{\text {het }}$ corresponds to the characteristic time of freezing of a droplet population for a given nucleation rate $J_{\text {het }}$. As the nucleation rate $J_{\text {het }}$ depends on temperature, this characteristic time for freezing is a function of temperature as well. For the INA- $\beta$, we can derive characteristic freezing times as discussed above based on both the simple exponential fit applied to $J_{\text {het }}$ and also based on SBM. Due to the narrow contact angle distribution, values for these two approaches are very similar. The following values result at different temperatures (values obtained from SBM are given in parentheses): at $T=-17^{\circ} \mathrm{C}: \tau_{\beta}=$ $15.9 \mathrm{~s}(28.3 \pm 3.8 \mathrm{~s})$; at $T=-18^{\circ} \mathrm{C}: \tau_{\beta}=1 \mathrm{~s}(1.1 \pm 0.1 \mathrm{~s})$; at $T=-19^{\circ} \mathrm{C}: \tau_{\beta}=0.06 \mathrm{~s}(0.07 \pm 0.01 \mathrm{~s})$; and at $T=-20^{\circ} \mathrm{C}$ : $\tau_{\beta}=0.003 \mathrm{~s}(0.006 \pm 0.001 \mathrm{~s})$. As is to be expected, characteristic times for freezing decrease with decreasing temperature. Such nucleation-rate-based characteristic freezing times could be considered in order to appropriately set the time steps in atmospheric modeling applications and/or to judge if, for a given time step, a time-independent (singular) treatment of the freezing process is possible. In the latter case, the frozen droplet fraction could be easily determined from the CHESS model by the limit of Eq. (4) for time $t$ to infinity, i.e., $f_{\text {ice }}=1-\exp (-\lambda)$. In other words, based on $\lambda$ only, the frozen droplet fraction can be determined if the nucleation process is fast compared to the model time step ( $\tau_{\text {ice }}$ is smaller than approximately one-third of the model time step).

Both approaches (nucleation rate alone and CHESS model together with nucleation rate) require information concerning the number of INA macromolecules present in the droplet population. This number could be easily determined having particle number and mass concentrations as model variables and, for example, the number of INA macromolecules per particle mass as a parameter. However, it should be noted that the number of INA macromolecules per particle mass is currently a parameter that is not known. But following what we said above, concerning the abundance of INA macromolecules, they might play a nonnegligible role 
in atmospheric ice nucleation, and hence research that helps to set limits on their abundance is strongly needed.

\section{Summary and conclusion}

In this study the immersion freezing behavior of birch pollen washing water was investigated at the Leipzig Aerosol Cloud Interaction Simulator (LACIS). Particles generated from washing water from two different birch pollen samples - one from the Czech Republic (Czech birch pollen) and one from Sweden (Swedish birch pollen) - were used to quantify their freezing behavior as a function of temperature. Particles generated from Czech birch pollen washing water showed a logarithmically linear increase of the ice fraction with decreasing temperature in a temperature range between -19 and $-23^{\circ} \mathrm{C}$. With further cooling the ice fraction leveled off to a constant value.

However, particles generated from the Swedish birch pollen washing water showed a somewhat different behavior. A saturation range was also found for the lower temperatures, but for the increase of the ice fraction, two different slopes were observed. In the temperature range between -17 and $-20^{\circ} \mathrm{C}$, the ice fraction increased more steeply than for the Czech birch pollen sample, but with further cooling the increase became shallower and showed a slope similar to the Czech birch pollen sample. Assuming that immersion freezing is caused by INA macromolecules (Pummer et al., 2012), we conclude first, based on the existence of a plateau region, that not all droplets contain an INA macromolecule, second that at least two different types of INA macromolecules do exist, and third that one of these types is present in both Swedish and Czech birch pollen washing water. Following the approach of Hartmann et al. (2013), we calculated the average number $\lambda$ of INA macromolecules in one particle by assuming the INA macromolecules to be Poisson distributed over the whole particle population. Furthermore, by using the newly developed CHESS model (Hartmann et al., 2013), the heterogeneous ice nucleation rates for the two different INA macromolecule types, $J_{\text {het, } \alpha}$ and $J_{\text {het }, \beta}$, could be determined based on the measured ice fractions and was parameterized as a function of temperature. $J_{\text {het, } \beta}$ showed a much steeper increase with decreasing temperature than $J_{\text {het, } \alpha}$ that was found in both birch samples. The application of the Soccer ball model (Niedermeier et al., 2011b) that represents a more accurate, albeit also more complicated, parameterization method showed a similar result. The contact angle distribution of the INA- $\beta$ features a slightly lower mean value $\mu$ and a much smaller standard deviation $\sigma$ than INA- $\alpha$. From that we concluded that the INA- $\beta$ is more homogeneous with respect to its ice-nucleation-related properties (i.e., contact angle) than the INA- $\alpha$. Both parameterizations (exponential fit and SBM) of the nucleation rate determined in this work for the INA- $\beta$ macromolecule can directly be used in cloud or larger scale models to describe heterogeneous freezing processes induced by these INA macromolecules. However, as the contact angle distribution of INA- $\alpha$ is quite broad, an extrapolation of the exponential fit parameterization to temperature and time ranges outside of those shown here should be done with caution as it might result in an overestimation of the nucleation rate. So only the SBM parameterization of $J_{\text {het }, \alpha}$ is valid for the whole temperature and time range.

To summarize, it can be said that the INA macromolecules that can be found on birch pollen grains are efficient ice nuclei. They nucleate ice at temperatures higher than $-20^{\circ} \mathrm{C}$ and are more efficient than most of the nonbiological particles (e.g., mineral dust; see, e.g., Murray et al., 2012; Hoose and Möhler, 2012). To date, the abundance of INA macromolecules in the atmosphere has not been determined, but the possibility of multiplication of pollen fragments by, for example, rain bursting was already shown (Schäppi et al., 1999). So it is possible that the importance of pollen for the ice nucleation in the atmosphere has been underestimated until now.

\section{Appendix A}

\section{Testing different model assumptions}

Figure A1 shows frozen fractions originating from the immersion freezing experiments with particles generated from Czech birch pollen washing water compared to results from additional model calculations. On the one hand, the gray solid line shows the frozen fraction calculated based on the simple approach $f_{\text {ice }}(T)=\left(1-\exp \left(-J_{\text {het }}(T) t\right)\right)$ using the exponential fit to describe the nucleation rate (Eq. (5), straight line) without including the information of an average number of $\operatorname{IN}(\lambda)$ in the droplets. That means we assumed that there is exactly one IN in every droplet. The measured slope of the ice fraction is represented well by the model results but the saturation range cannot be reproduced. On the other hand, the red, black and green dotted lines are results from the CHESS model including a heterogeneous nucleation rate based on CNT using a single contact angle (i.e., $\theta=54.43^{\circ}$ ). The measured saturation range is represented well due to the fact that the average number of IN per droplet, i.e., $\lambda$, was accounted for. However, the measured increase of the frozen fractions in the temperature range above $-24^{\circ} \mathrm{C}$ is not reproduced by the model.

\section{Appendix B}

\section{The number of INA macromolecules per pollen grain}

The number of INA macromolecules per pollen grain was estimated as follows: a birch pollen grain is known to have an average size of about $25 \mu \mathrm{m}$ (Diehl et al., 2001) and it can be assumed to be spherical (see, e.g., SEM pictures by Pummer et al., 2012, and Grote et al., 1989). A density of 


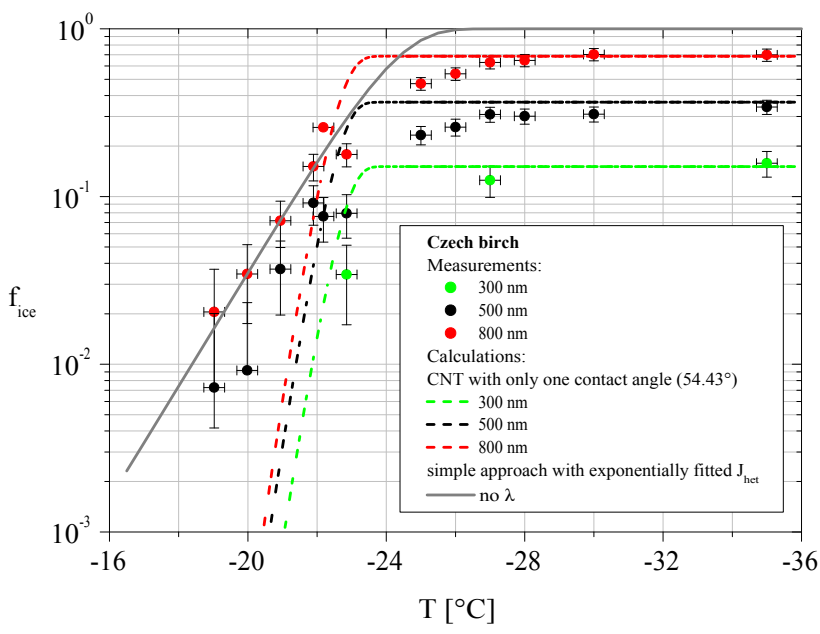

Fig. A1. Ice fraction $f_{\text {ice }}$ as a function of temperature $T$ for 300 , 500 and $800 \mathrm{~nm}$ Czech birch pollen washing water particles (dots) and different model calculations. For explanations see Appendix A.

$1 \mathrm{~g} \mathrm{~cm}^{-3}$ was assumed (Niklas, 1985). From this the number of pollen grains in $1 \mathrm{~g}$ of the pollen sample can be estimated to be $1.2 \times 10^{8}$.

A sample was prepared similarly to the procedure described in the main text, and both the solution/suspension and also the pollen caught in the filter were dried and weighted. The amount of material found in the solution/suspension was $0.3 \mathrm{~g}$, i.e., $30 \%$ of the original pollen mass.

For a particle of known size, the dry mass can be calculated, again assuming spherical particles and a density of the suspended material of about $1.6 \mathrm{~g} \mathrm{~cm}^{-3}$ (assumed average density for soluble pollen surface material). The average number of macromolecules in a particle $\lambda$ as a function of particle size is known, and with this the average number of macromolecules per particle mass.

By setting the particle mass in relation to the total suspended mass, we can derive the number of macromolecules per pollen grain, which results in values of about $2 \times 10^{4}$. The above-described procedure assumes that the particles dissolve completely. If this were not the case and only an outer shell of the particles were to go into solution, then the number of macromolecules per pollen grain would even increase, making it safe to assume that each birch pollen grain carries several thousands of macromolecules.

Additionally, a further rough estimation yields the fraction of the material that is ice active compared to the total amount of material that can be washed of the pollen. For this, the size of the dry particles at $\lambda=1$ (i.e., where a particle on average contains one INA macromolecule) can be determined to be around $740 \mathrm{~nm}$ for the Czech pollen sample and $440 \mathrm{~nm}$ for the Swedish. Assuming the INA macromolecule to be spherical and to have a size of $10 \mathrm{~nm}$, the volume fraction of the INA macromolecule, compared to the total parti- cle, is $0.001 \%$ for the Swedish pollen sample and $0.0002 \%$ for the Czech. While this is only a crude estimate, it clearly shows that the volume fraction of ice-active material can be expected to be very small. However, it should once again be mentioned that it is most likely not the volume fraction but the absolute number of INA macromolecules present in a droplet that controls the freezing behavior.

Acknowledgements. This research project was partly funded by the German Research Foundation (DFG project WE 4722/1-1) within the DFG Research Unit FOR 1525 INUIT. We want to thank MicroDICE for funding a short visit (\#4989). Furthermore, we want to thank Pharmallerga for the donation of pollen samples. B. Pummer and H. Grothe are grateful for support from Vienna University of Technology within the innovative project "The impact of biological structures on ice nucleation". H. Grothe acknowledges support from the FWF within the project "Freezing and microphysics of PSCs and cold cirrus ice clouds" (P23027).

Edited by: O. Möhler

\section{References}

Breiteneder, H., Pettenburger, K., Bito, A., Valenta, R., Kraft, D., Rumpold, H., Scheiner, O., and Breitenbach, M.: The gene coding for the major birch pollen allergen Betv1, is highly homologous to a pea disease resistance response gene, EMBO J., 8, 1935-1938, 1989.

Broadley, S. L., Murray, B. J., Herbert, R. J., Atkinson, J. D., Dobbie, S., Malkin, T. L., Condliffe, E., and Neve, L.: Immersion mode heterogeneous ice nucleation by an illite rich powder representative of atmospheric mineral dust, Atmos. Chem. Phys., 12, 287-307, doi:10.5194/acp-12-287-2012, 2012.

Clarke, A., Gleeson, P., Harrison, S., and Knox, R. B.: Pollenstigma interactions: Identification and characterization of surface components with recognition potential, Proc. Natl. Acad. Sci. USA, 76, 3358-3362, 1979.

Clauss, T., Kiselev, A., Hartmann, S., Augustin, S., Pfeifer, S., Niedermeier, D., Wex, H., and Stratmann, F.: Application of linear polarized light for the discrimination of frozen and liquid droplets in ice nucleation experiments, Atmos. Meas. Tech., 6, 1041-1052, doi:10.5194/amt-6-1041-2013, 2013.

Conen, F., Morris, C. E., Leifeld, J., Yakutin, M. V., and Alewell, C.: Biological residues define the ice nucleation properties of soil dust, Atmos. Chem. Phys., 11, 9643-9648, doi:10.5194/acp-119643-2011, 2011.

Diehl, K., Quick, C., Matthias-Maser, S., Mitra, S. K., and Jaenicke, R.: The ice nucleating ability of pollen. Part I: Laboratory studies in deposition and condensation freezing modes, Atmos. Res., 58, 75-87, 2001.

Diehl, K., Matthias-Maser, S., Jaenicke, R., and Mitra, S. K.: The ice nucleating ability of pollen: Part II. Laboratory studies in immersion and contact freezing modes, Atmos. Res., 61, 125-133, 2002.

Dingle, A. N.: Pollen as condensation nuclei, J. Rech. Atmos., 2, 232-237, 1966.

Durham, O. C.: Methods in aerobiology, J. Aviation Med., 12, 153 162,1941 . 
Franze, T., Weller, M. G., Niessner, R., and Pöschl, U.: Protein nitration by polluted air, Environ. Sci. Technol. 39, 1673-1678, doi:10.1021/es0488737, 2005.

Govindarajan, A. G. and Lindow, S. E.: Size of bacterial icenucleation sites measured in situ by radiation inactivation analysis, Proc. Natl. Acad. Sci. USA, 85, 1334-1338, 1988.

Graether, S. P. and Jia, Z.: Modeling Pseudomonas syringae IceNucleation Protein as a beta-helical protein, Biophysical Journal, 80, 1169-1173, 2001.

Grote, M.: Techniques to preserve soluble surface components in birch pollen wall: A scanning and transmission electron microscopic study, J. Histochem. Cytochem., 37, 981-987, 1989.

Hartmann, S., Niedermeier, D., Voigtländer, J., Clauss, T., Shaw, R. A., Wex, H., Kiselev, A., and Stratmann, F.: Homogeneous and heterogeneous ice nucleation at LACIS: operating principle and theoretical studies, Atmos. Chem. Phys., 11, 1753-1767, doi:10.5194/acp-11-1753-2011, 2011.

Hartmann, S., Augustin, S., Clauss, T., Wex, H., Šantl-Temkiv, T., Voigtländer, J., Niedermeier, D., and Stratmann, F.: Immersion freezing of ice nucleation active protein complexes, Atmos. Chem. Phys., 13, 5751-5766, doi:10.5194/acp-13-57512013, 2013.

Hoose, C., Kristjansson, J. E., and Burrows, S. M.: How important is biological ice nucleation in clouds on a global scale?, Environ. Res. Lett., 5, 024009, doi:10.1088/1748-9326/5/2/024009, 2010.

Hoose, C. and Möhler, O.: Heterogeneous ice nucleation on atmospheric aerosols: a review of results from laboratory experiments, Atmos. Chem. Phys., 12, 9817-9854, doi:10.5194/acp-12-98172012, 2012.

Knutson, E. O. and Whitby, K. T.: Aerosol classification by electric mobility: Apparatus, theory and applications, J. Aerosol Sci., 6, 443-451, 1975.

Lindow, S. E.: Membrane fluidity as a factor in production and stability of bacterial ice nuclei active at high subfreezing temperatures, Cryobiology, 32, 247-258, 1995.

Lohmann, U.: A glaciation indirect aerosol effect caused by soot aerosols, Geophys. Res. Lett., 29, 1052, doi:10.1029/2001GL014357, 2002.

Maki, L. R., Galyan, E. L., Chang-Chien, M.-M., and Caldwell, D. R.: Ice nucleation induced by pseudomonas-syringae, Appl. Microbiol., 28, 456-459, 1974.

Murray, B. J., O'Sullivan, D., Atkinson, J. D., and Webb, M. E.: Ice nucleation by particles immersed in supercooled cloud droplets, Chem. Soc. Rev., 41, 6519-6554, 2012.

Niedermeier, D., Hartmann, S., Shaw, R. A., Covert, D., Mentel, T. F., Schneider, J., Poulain, L., Reitz, P., Spindler, C., Clauss, T., Kiselev, A., Hallbauer, E., Wex, H., Mildenberger, K., and Stratmann, F.: Heterogeneous freezing of droplets with immersed mineral dust particles - measurements and parameterization, Atmos. Chem. Phys., 10, 3601-3614, doi:10.5194/acp-10-36012010, 2010.

Niedermeier, D., Shaw, R. A., Hartmann, S., Wex, H., Clauss, T., Voigtländer, J., and Stratmann, F.: Heterogeneous ice nucleation: exploring the transition from stochastic to singular freezing behavior, Atmos. Chem. Phys., 11, 8767-8775, doi:10.5194/acp11-8767-2011, $2011 \mathrm{~b}$.

Niklas, K.: The aerodynamics of wind pollination, Botanical Review, 51, 328-386,1985.
Pan, K. M., Baldwin, M., Nguyen, J., Gasset, M., Serban, A., Groth, D., Mehlhorn, I., Huang, Z., Fletterick, R. J., Cohen, F. E., and Prusiner, S. B.: Conversion of alpha-helices into beta-sheets in the formation of the scrapie prion proteins, Proc. Natl. Acad. Sci USA, 90, 10962-10966, 1993.

Phillips, V. T. J., DeMott, P. J., and Andronache, C.: An empirical parameterization of heterogeneous ice nucleation for multiple chemical species of aerosol, J. Atmos. Sci., 65, 2757-2783, 2007.

Pratt, K. A., DeMott, P. J., French, J. R., Wang, Z., Westphal, D. L., Heymsfield, A. J., Twohy, C. H., Prenni, A. J., and Prather, K. A.: In situ detection of biological particles in cloud ice-crystals, Nature Geosci., 2, 397-400, 2009.

Pruppacher, H. R. and Klett, J. D.: Microphysics of Clouds and Precipitation, Kluwer Academic Publishers, Dordrecht, the Netherlands, 1997.

Pummer, B. G., Bauer, H., Bernardi, J., Bleicher, S., and Grothe, H.: Suspendable macromolecules are responsible for ice nucleation activity of birch and conifer pollen, Atmos. Chem. Phys., 12, 2541-2550, doi:10.5194/acp-12-2541-2012, 2012.

Pummer, B.: Ice nucleation activity of pollen and fungal spores, PhD Dissertation, Technische Universität Wien, 2013.

Schäppi, G. F., Taylor, P. E., Pain, M. C. F., Cameron, P. A., Dent, A. W., Staff, I. A., and Suphioglu, C.: Concentrations of major grass group 4 allergens in pollen grains and atmospheric particles: implications for hay fever and allergic asthma sufferers sensitized to grass pollen allergens, Clin. Exp. Allergy, 29, 633-641, 1999.

Schnell, R. C. and Vali, G.: Atmospheric ice nuclei from decomposing vegetation, Nature, 236, 163-165, 1972.

Schnell, R. C. and Vali, G.: Biogenic ice nuclei: part I. Terrestrial and marine sources, J. Atmos. Sci. 33, 1554-1564, 1976.

Schulte, F., Mäder, J., Kroh, L. W., Panne, U., and Kneipp, J.: Characterization of Pollen Carotenoids with in situ and HighPerformance Thin-Layer Chromatography Supported Resonant Raman Spectroscopy, Anal. Chem. 81, 8426-8433, 2009.

Storelvmo, T., Hoose, C., and Eriksson, P.: Global modeling of mixed phase clouds: The albedo and lifetime effects of aerosols, J. Geophys. Res.-Atmos., 116, D05207, doi:10.1029/2010JD014724, 2011.

Stratmann, F., Kiselev, A., Wurzler, S., Wendisch, M., Heintzenberg, J., Charlson, R. J., Diehl, K., Wex, H., and Schmidt, S.: Laboratory studies and numerical simulations of cloud droplet formation under realistic supersaturation conditions, J. Atmos. Ocean. Tech., 21, 876-887, 2004.

Szyrmer, W. and I. Zawadzki: Biogenic and anthropogenic sources of ice forming nuclei: A review, B. Am. Meteorol. Soc., 78, 209228, 1997.

Takahashi, T., Tanaka, M., Brannan, C. I., Jenkins, N. A., Copeland, N. G., Suda, T., and Nagata, S.: Generalized lymphoproliferative disease in mice, caused by a point mutation in the Fas ligand, Cell, 76, 969-976, 1994.

Vali, G.: Quantitative Evaluation of Experimental Results an the Heterogeneous Freezing Nucleation of Supercooled Liquids, J. Atmos. Sci., 28, 402-409, 1971

von Blohn, N., Mitra, S. K., Diehl, K., and Borrmann, S.: The ice nucleating ability of pollen. Part III: New laboratory studies in immersion and contact freezing modes including more pollen types, Atmos. Res., 78, 182-189, 2005. 
Wolber, P. K., Deininger, C. A., Southworth, M. W., Vandekerckhove, J., Vanmontagu, M., and Warren, G. J.: Identification and purification of a bacterial ice-nucleation protein, Proc. Natl. Acad. Sci. USA, 83, 7256-7260, 1986.

Wright, T. P. and Petters, M. D.: The role of time in heterogeneous freezing nucleation, J. Geophys. Res.-Atmos., 118, 3731-3743, doi:10.1002/jgrd.50365, 2013.
Yttri, K. E., Dye, C., and Kiss, G.: Ambient aerosol concentrations of sugars and sugar-alcohols at four different sites in Norway, Atmos. Chem. Phys., 7, 4267-4279, doi:10.5194/acp-7-4267-2007, 2007.

Zobrist, B., Koop, T., Luo, B. P., Marcolli, C., and Peter, T.: Heterogeneous ice nucleation rate coefficient of water droplets coated by a nonadecanol monolayer, J. Phys. Chem. C, 111, 2149-2155, 2007. 